\title{
Computation of water hammer protection of modernized pumping station
}

\author{
Daniel Himr ${ }^{1, a}$
}

VŠB - Technical University of Ostrava, Faculty of Mechanical Engineering, Department of Hydrodynamics and Hydraulic Equipment, 17. listopadu 15, 708 33, Ostrava, Czech Republic

\begin{abstract}
Pumping station supplies water for irrigation. Maximal capacity $2 \times 1.2 \mathrm{~m}^{3} \cdot \mathrm{s}^{-1}$ became insufficient, thus it was upgraded to $2 \times 2 \mathrm{~m}^{3} \cdot \mathrm{s}^{-1}$. Paper is focused on design of protection against water hammer in case of sudden pumps trip.

Numerical simulation of the most dangerous case (when pumps are giving the maximal flow rate) showed that existing air vessels were not able to protect the system and it would be necessary to add new vessels. Special care was paid to influence of their connection to the main pipeline, because the resistance of the connection has a significant impact on the scale of pressure pulsations.

Finally, the pump trip was performed to verify if the system worked correctly. The test showed that pressure pulsations are lower (better) than computation predicted. This discrepancy was further analysed.
\end{abstract}

\section{Introduction}

Pumping station (PS) Al-Shabab in Egypt provides a water supply for an irrigation. It transports water from a river through two discharge pipes to a reservoir $4.5 \mathrm{~km}$ far. Water level of the reservoir is $25.8 \mathrm{~m}$ to $27.93 \mathrm{~m}$ above the river. Maximal capacity of the PS $2 \times 1.2 \mathrm{~m}^{3} \cdot \mathrm{s}^{-1}$ was found as insufficient, so it was decided to increase the maximal flow rate to $2 \times 2 \mathrm{~m}^{3} \cdot \mathrm{s}^{-1}$.

It meant to install new pumps and new air vessels, which would serve as a protection against a water hammer in case of a black-out. Czech company Sigma Invest provided modernization and asked me for computational simulation of water hammer due to pump trip to design an appropriate size of the air vessels.

Sudden pump trip while giving a maximal flow rate is one of the most dangerous situations, which can occur in the PS. When pump is working, it provides pressure and flow, which are given by an intersection of a pump characteristic and a pipeline characteristic. The point of intersection is called operating point, see figure 1 . One can say



Fig. 1. Operating point of the system

\footnotetext{
a e-mail: daniel.himr@vsb.cz
}

that energy supplied by the pump and energy lost in the pipeline are in equilibrium. Also, torque by a motor is in equilibrium with torque by water flowing through an impeller and friction in bearings of the pump, so it has a constant speed.

If motor loses the energy, because of a black-out, a torque imbalance occurs and the pump starts decelerating. While the speed of the impeller goes down, the pump characteristic changes according to the affinity law, see equations 1 to 3, where subscript $c$ means current and $o$ means original.

$$
\begin{aligned}
\frac{Q_{\mathrm{c}}}{Q_{\mathrm{o}}} & =\frac{n_{\mathrm{c}}}{n_{\mathrm{o}}}, \\
\frac{Y_{\mathrm{c}}}{Y_{\mathrm{o}}} & =\left(\frac{n_{\mathrm{c}}}{n_{\mathrm{o}}}\right)^{2}, \\
\frac{T_{\mathrm{c}}}{T_{\mathrm{o}}} & =\left(\frac{n_{\mathrm{c}}}{n_{\mathrm{o}}}\right)^{2} .
\end{aligned}
$$

As inertia of water column keeps flow rate the same as before the black-out, the operating point moves to another part of characteristic. This process is depicted in the figure 2 .

This part of characteristic is usually unmeasured, thus it is quite difficult to perform a computational simulation, because the pump characteristic becomes undefined. Pump can work as a brake or a turbine at this moment. It makes pressure going down and when it is low enough it can cause a collapse of pipe anywhere in the pipeline [5], because the low pressure travels through the entire pipeline as a shock wave till it reaches the reservoir at the end of the system. The shock wave is reflected and travels back towards the pump.

As soon as it reaches a check valve, which does not allow a back flow, the resulting overpressure can be higher than allowed maximal pressure in the pipeline. It can leads to destruction of the pumping station. Pressure can even exceed the Joukowsky value [1], [2]. It happens when column separation appears during the first phase of water ham- 


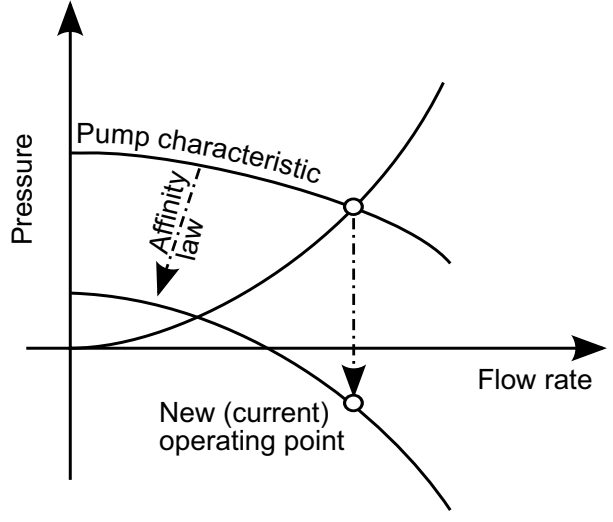

Fig. 2. Movement of the operating point

mer (low pressure). The process is repeating till a new steady state is reached. It is a zero flow rate in this case.

Negative impact of the water hammer can be suppressed with sufficiently big air vessel placed near to the PS. The vessel supplies water into the discharge pipe immediately after the pump trip. It does not allow the pressure to fall too much and protects pipeline against collapse or column separation. Air in the vessel reduces a maximal overpressure in the second phase.

\section{Old set-up}

PS Al-Shabab consists of five pumps and two main discharge pipes (DN 1000, $4.5 \mathrm{~km}$ length). Each two units feed one discharge pipe and one unit serves as a reserve in case of troubles. Before the modernization, maximal flow rate was $2 \times 1.2 \mathrm{~m}^{3} \cdot \mathrm{s}^{-1}$ and each discharge pipe was protected with a pressure vessel $\left(30 \mathrm{~m}^{3}\right)$, see figure 6 . Altitude of the pipeline is showed in figure 3 .

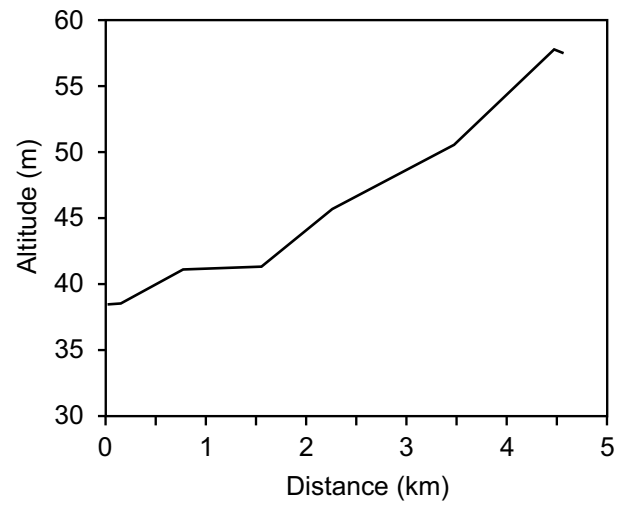

Fig. 3. Altitude of the pipe line; $P S$ is placed at $0 \mathrm{~km}$

Unfortunately, no measurement of the old state was available. Exactly, all documentation was available, but no measurement of transient or, at least, steady state had been done.

Despite this fact, a numerical simulation of a black-out was performed to validate the model, which was arranged according to the given technical documentation.

Figure 4 shows the pressure next to the check valve and in the air vessel. Pumps tripped at 5th second when the flow rate was $1.2 \mathrm{~m}^{3} \cdot \mathrm{s}^{-1}$. The pressure next to the check valves goes down almost reaching the value 1 bar, then growing to 8 bar. The lowest pressure was found $3.5 \mathrm{~km}$ far from PS, but its value was greater than value of vaporization. As the pipeline is PN10, probably, the numerical model is correct. The measurement is really missing here.

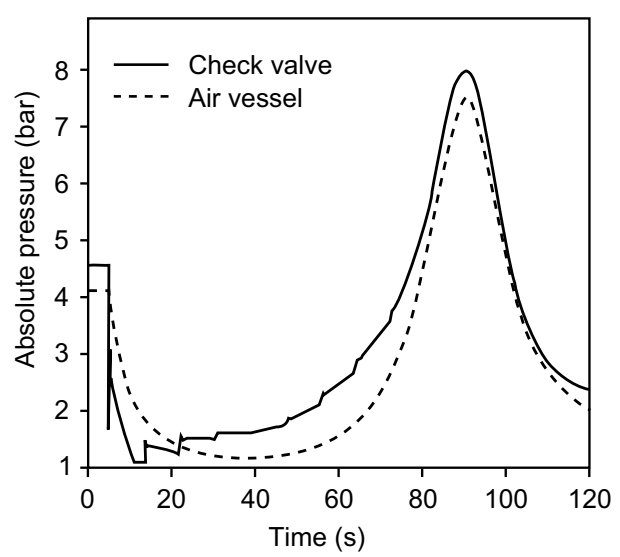

Fig. 4. Simulation of a black-out in the old set-up

\section{New set-up}

Stronger units replaced the old pumps and maximal flow rate increased to value $2 \times 2 \mathrm{~m}^{3} \cdot \mathrm{s}^{-1}$. The Egyptian customer required that maximal pressure must not exceed 6 bar (abs.), because the discharge pipes are old and they might not be PN10 any more.

As a revision of the old air vessels proved their good condition, they stayed at the place and were accompanied with new vessels (produced by Sigma), so each discharge pipe is protected by two tanks $\left(2 \times 30 \mathrm{~m}^{3}\right)$, see figure 8 . Numerical simulation showed, that protection provided by the vessels is sufficient, when connections of vessels to the discharge pipe have well tuned resistance, which is given by its geometrical properties and can by controlled with a valve marked in the figure 8 .

Customer wanted to make him sure and asked Egyptian Hydraulic Research Institute (HRI) for a competitive computation. Computation for Sigma and HRI computation (for Egyptian customer) are compared in the figure 5. Result by HRI gives high pressure peak next to the PS,

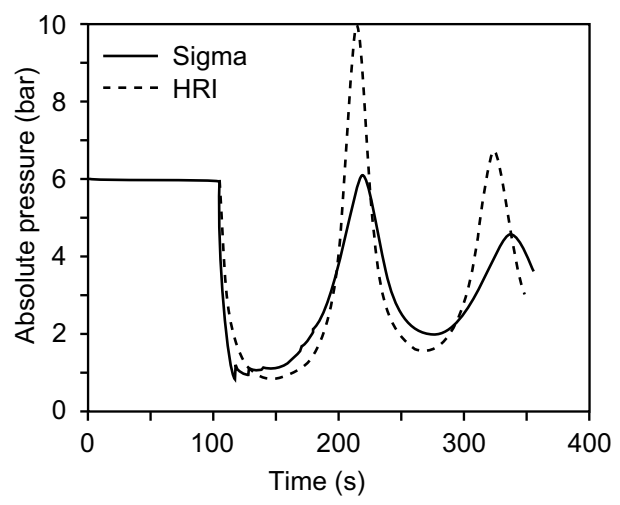

Fig. 5. Predicted pressure next to the PS during a black-out by different computational models 


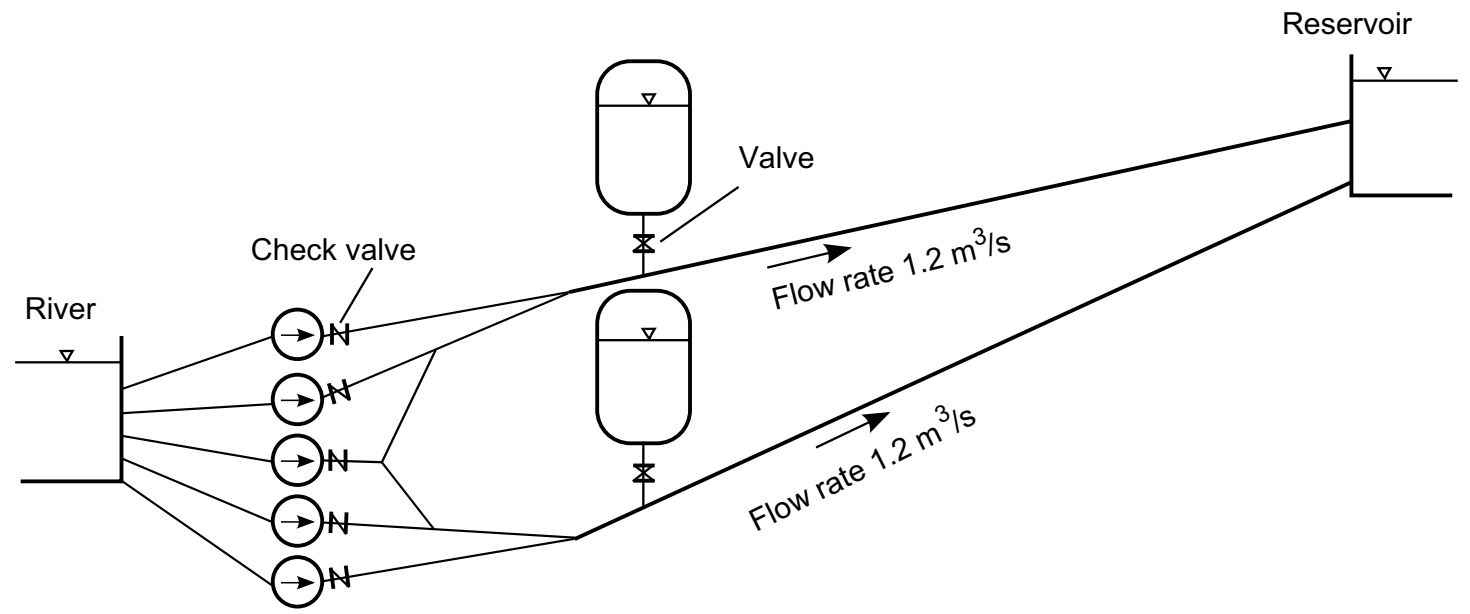

Fig. 6. Simplified scheme of the old set-up

so they declared that two vessels $\left(30 \mathrm{~m}^{3}\right.$ each) would not be sufficient and suggested increasing their volume (from $30+30$ to $30+48 \mathrm{~m}^{3}$ ). They supported the suggestion with computation, see figure 7 . The question was: Why did not

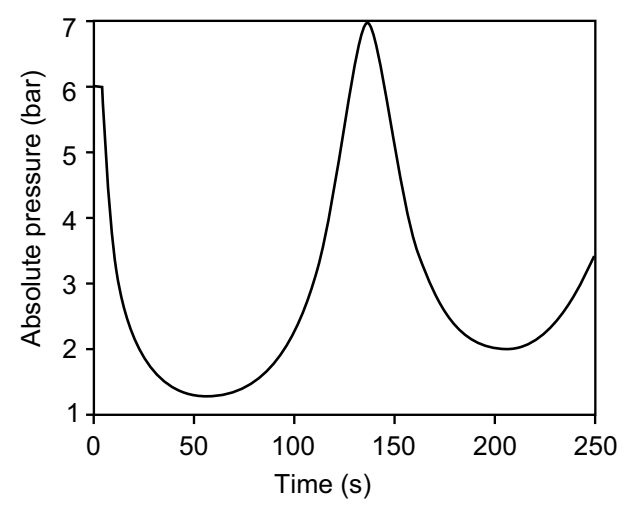

Fig. 7. HRI computation of pressure pulsations next to the PS with bigger volume of new vessels

simulations correspond to each other at all?

\section{Computational models}

Simulation for Sigma was done with Hydra software, which had been developed by Brno University of Technology. It can solve a non-steady flow in pipeline systems as onedimensional. Momentum equation (4) and continuity equation (5) are solved by Lax-Wendroff method. One can find more information on it in [3].

$$
\begin{aligned}
\frac{\partial Q}{\partial t}+\frac{S}{\rho} \frac{\partial p}{\partial x}+\frac{\lambda}{2 D S}|Q| Q & =S g_{p}, \\
\frac{\partial p}{\partial t}+\frac{K}{S} \frac{\partial Q}{\partial x} & =f(p, t) .
\end{aligned}
$$

Hydraulic elements are defined by boundary conditions. Reservoir and river are points with a constant pressure, pump is described by a dependence of a specific energy and a torque on the flow rate. Check valve is defined by a resistance when flow has one direction and does not allow flowing in the other direction.
Air vessel is partially filled by water and partially by air. Thus, one has to prescribe an initial volume of air and a pressure. Then, the state of air is described by the equation (6).

$$
p V^{s}=p_{0} V_{0}^{s}
$$

where subscript 0 means initial state. A part of this boundary condition is also resistance of vessel connection to the discharge pipe.

The resistance determines pressure loss when water is flowing into/out of the vessel. It also influences maximal pressure during water hammer, see equation (7) and figure 9. Obviously, the higher resistance, the lower maximal pressure and the lower minimal pressure (risk of cavitation increases). The relationship between resistance $R$ and local loss coefficient $\xi$ is described by equation 8 .

Lower resistance makes emptying the vessel easier. It leads to bigger required volume of water inside. Careful numerical analysis found the best option, when minimal pressure is high enough, to suppress any risk of cavitation and maximal pressure slightly exceeds 6 bar. It broke customer's requirement, but it was accepted.

$$
\begin{gathered}
\Delta p=R|Q| Q \\
R=\frac{8 \rho \xi}{\pi^{2} D^{4}}
\end{gathered}
$$

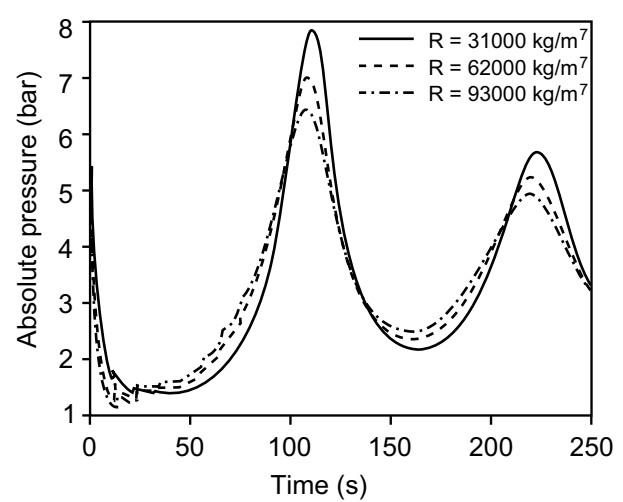

Fig. 8. Scale of pressure pulsations for different resistance of vessel connection to the discharge pipe 


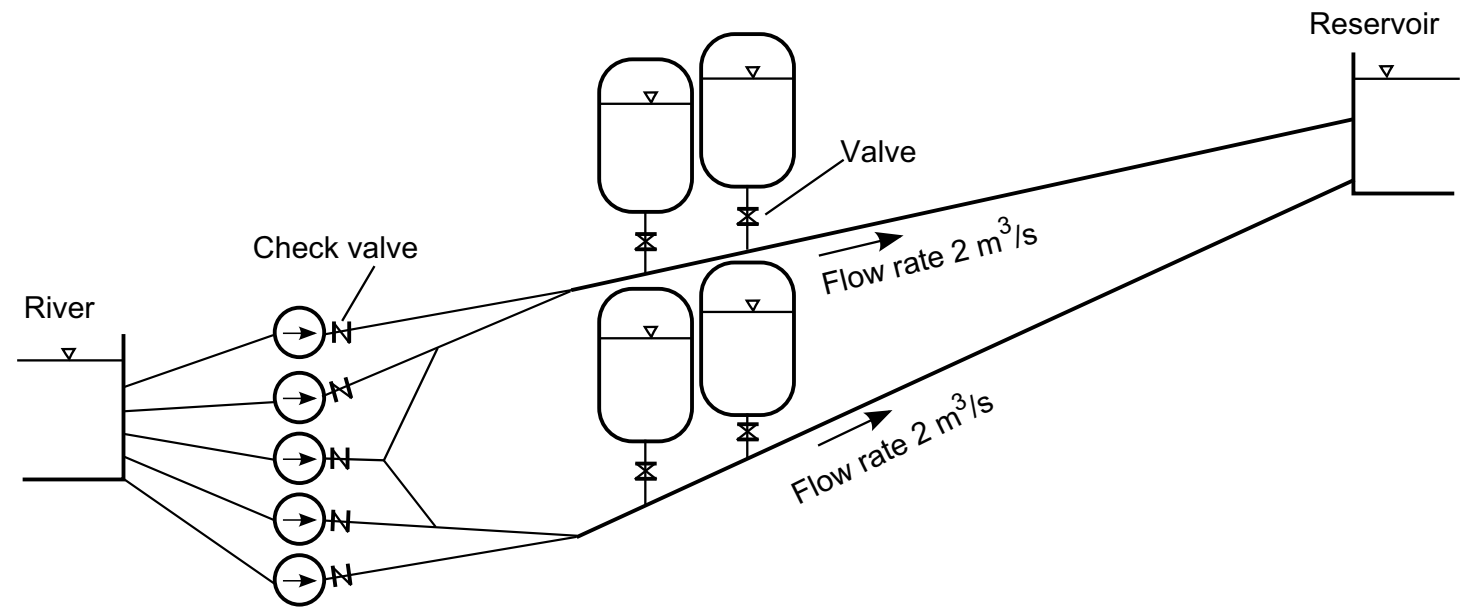

Fig. 9. Simplified scheme of the new set-up. New air vessels accompanied old vessels

Hydraulic Research Institute used Wanda software to simulate pump trip. It is a commercial software by Deltares. It computes flow in pipeline similarly like Hydra, but it uses method of characteristic to solve equations (4), (5) and the same boundary conditions are available.

HRI gave data about their model and careful analysis discovered that they neglected the resistance of the vessel connection so it explained such a big pressure pulsations.

Omission of the resistance is a quite big mistake, because, as shown in figure 9, the sensitivity of the pressure peaks on it is high.

As the result by HRI turned out as incorrect, it was decided to continue building without any change of the project.

\section{Measurement on the location}

When building was finished, a field test was done to realize if the system works correctly. Two new pumps feeding one discharge pipe were stopped to simulate a black-out. Pressure was measured next to the PS and $2.2 \mathrm{~km}$ behind the PS. Unfortunately, it was not possible to measure at more places, since the pipeline is underground and nobody wanted to dig.

Figures 10 and 11 show comparison of measured pressure pulsations and predicted ones by Hydra.

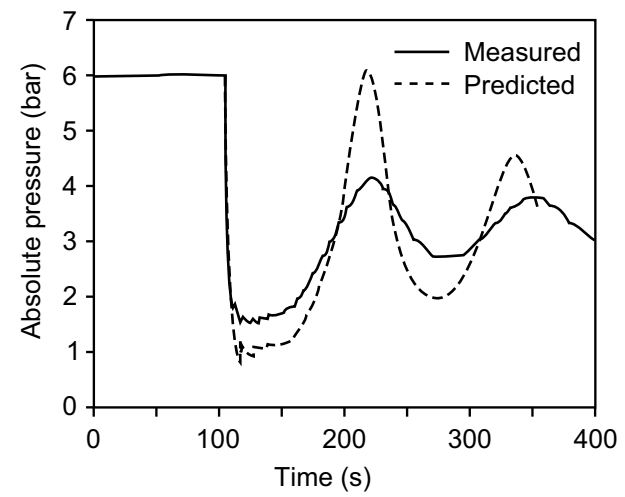

Fig. 10. Pressure pulsations during a pump trip next to the PS

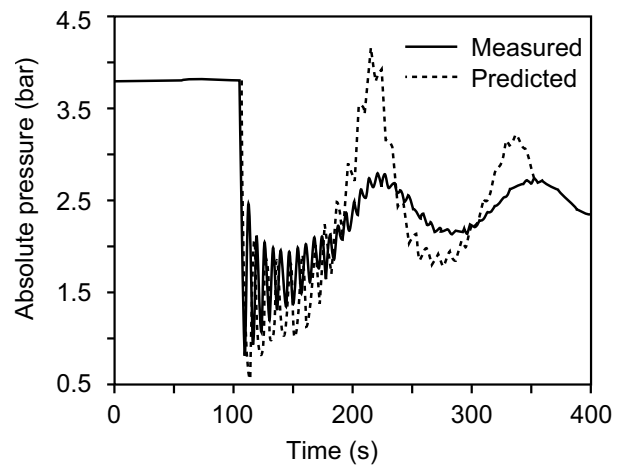

Fig. 11. Pressure pulsations during a pump trip $2.2 \mathrm{~km}$ downstream the PS

Reality was much better than prediction. Pulsations were lower than expected and minimal pressure was in the save limits, so there is no risk of cavitation.

But there is a small blemish: Maximal flow rate was only $1.8 \mathrm{~m}^{3} / \mathrm{s}$ instead of required $2.0 \mathrm{~m}^{3} / \mathrm{s}$. Probably, the discharge pipe needs cleaning. This defect would not have appeared if the old state had been properly measured, but this is not a main reason, why the pulsations were lower than predicted.

The realisation had one issue: How to set the resistance of the vessel connection? Its value was given by computation, but it is just a number. Diameter and length of the connecting pipe was designed according to this number (Idelchik [4] was very helpful) and a throttling valve was add to control the resistance.

During the testing the valve opening was changed to reach a desired run of pressure pulsations. It took several days, because it was not allowed to stop the pumps whenever; the water supply had to be kept.

Careful measurement of the old vessels proved that their volume is $34.88 \mathrm{~m}^{3}$, thus it was possible to have more air inside. So, total volume of two vessels is $64.88 \mathrm{~m}^{3}$ and total volume of air is $20.1 \mathrm{~m}^{3}$ instead of originally prescribed $16 \mathrm{~m}^{3}$. Also, it was possible to set higher resistance of the vessel connection.

Refined numerical model fits measurement better and allows us to look at the pressure along the all discharge pipe. Results of the refined numerical model are shown in figures 12, 13 and pressure along the pipeline is plotted in 
the figure 14. Obviously, the pressure does not go under $50 \mathrm{kPa}$ (abs.) anywhere in the pipeline.

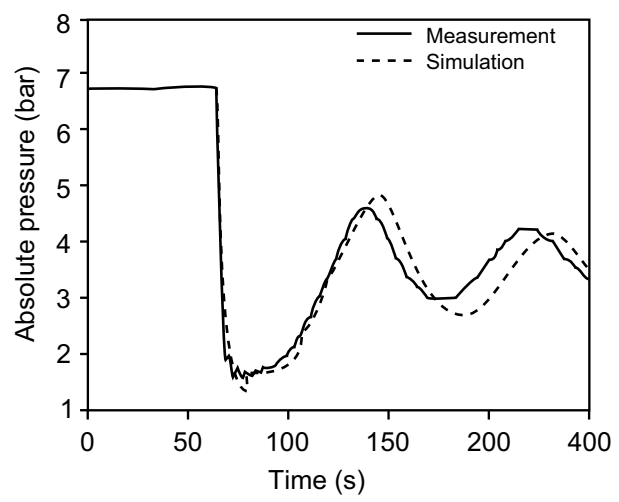

Fig. 12. Pressure pulsations during a pump trip next to the PS (refined numerical model)

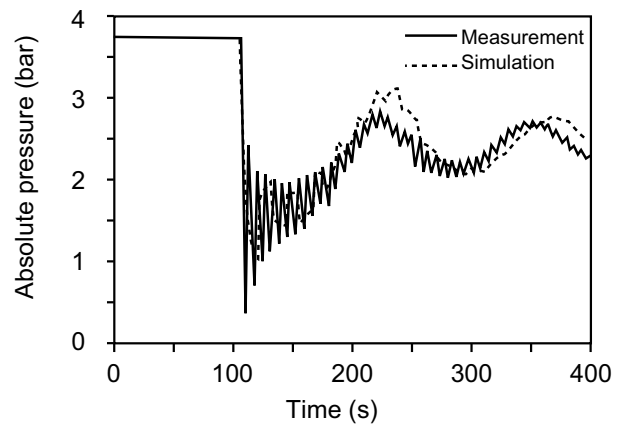

Fig. 13. Pressure pulsations during a pump trip $2.2 \mathrm{~km}$ downstream the PS (refined numerical model)

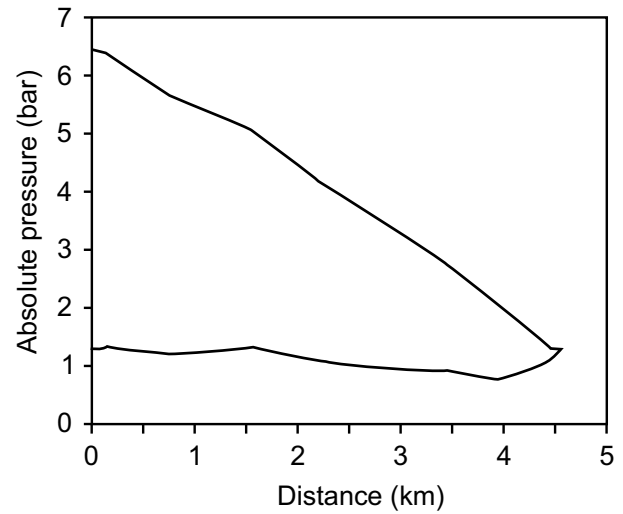

Fig. 14. Computed maximal and minimal pressure along the pipeline, PS is placed at the $0 \mathrm{~km}$

\section{Conclusion}

Problems with modernization of a pumping station were described. Paper is focused on the protection against water hammer, which can be induced due to black-out.

Two independent discharge pipes were protected with two vessels, which would not be sufficient after installation of new pumps, which are able to give almost two times greater flow rate than old units.

Despite the lack of information about PS before the modernization (technical documentation was available, but no measurement of transient) a numerical model of the system was successfully created. The model helped to suggest an appropriate dimension of air vessels, which protect pipeline against a water hammer. Unknown parameters of the system were chosen slightly worse than expected to keep the results on the safe side.

Beside the volume of air in the vessel, attention was paid also to a resistance of their connection to the discharge pipe. The resistance strongly influences the scale of pressure pulsation and cannot be neglected.

After finishing the construction, measurement of pressure pulsations caused by stopping the pumps showed better results than predicted. This pleasant discrepancy was further analysed and it was found that volume of the old air vessel in the documentation does not correspond to the real volume, which is greater.

\section{Acknowledgement}

This paper was elaborated in the framework of the project Opportunity for young researchers, reg. no. CZ.1.07/2.3.00/ 30.0016, supported by Operational Programme Education for Competitiveness and co-financed by the European Social Fund and the state budget of the Czech Republic.

I would like to thank Sigma Invest for their kind permission to publish this paper.

\section{Nomenclature}

$\begin{array}{lll}D & (\mathrm{~m}) & \begin{array}{l}\text { Diameter } \\ f\end{array} \\ \left(\mathrm{~Pa} \cdot \mathrm{s}^{-1}\right) & \begin{array}{l}\text { Function of pipe wall pulsations } \\ \text { due to pressure changes }\end{array} \\ g_{p} & \left(\mathrm{~m} \cdot \mathrm{s}^{-2}\right) & \begin{array}{l}\text { Projection of gravitational accelera- } \\ \text { tion onto pipe axis }\end{array} \\ K & (\mathrm{~Pa}) & \begin{array}{l}\text { Bulk modulus } \\ \text { Rotational speed }\end{array} \\ n & (\mathrm{rps}) & \text { Pressure } \\ p & (\mathrm{~Pa}) & \text { Discharge } \\ Q & \left(\mathrm{~m}^{3} \mathrm{~s}^{-1}\right) & \text { Resistance } \\ R & \left(\mathrm{~kg} \cdot \mathrm{m}^{-7}\right) & \text { Pipe cross-section } \\ S & \left(\mathrm{~m}^{2}\right) & \text { Polytropic exponent } \\ s & (-) & \text { Torque } \\ T & (\mathrm{~N} \cdot \mathrm{m}) & \text { Time } \\ t & (\mathrm{~s}) & \text { Volume } \\ V & \left(\mathrm{~m}^{3}\right) & \text { Longitudinal coordinate } \\ x & (\mathrm{~m}) & \text { Specific energy } \\ Y & (\mathrm{~J} / \mathrm{kg}) & \text { Pressure loss } \\ \Delta p & (\mathrm{~Pa}) & \text { Coefficient of friction loss } \\ \lambda & (-) & \text { Density } \\ \rho & \left(\mathrm{kg} \cdot \mathrm{m}^{-3}\right) & \text { Local loss coefficient } \\ \xi & (-) & \end{array}$

\section{References}

1. Bergant, A., Simpson, A. R., Tijsseling, A.S., Journal of Fluids and Structures 22 (2006) pp. 135 - 171 
2. Autrique, R. et al. , IOP Conference Series: Earth Environtal Science 15022014 (2012) pp. 8, doi:10.1088/1755-1315/15/2/022014

3. Himr, D. Habán, V., IOP Conference Series: Earth Environtal Science 12012087 (2010) pp. 8, doi:10.1088/1755-1315/12/1/012087

4. I. E. Idelchik, Handbook of Hydraulic Resistance (CRC Press, Inc., 1994) pp. 181

5. Pejovic, S., Boldy, A. P., Guidlines to Hydraulic Transient Analysis of Pumping Systems (P \& B Press, Belgrade; Coventry 1992) pp. 181 